\title{
Research Paper: The Verbal \& Non-Verbal Communication Screening Checklist for Persian Speaking Children From 12 to 24 Months and Its Validity and Reliability
}

Niloofar Safariyan ${ }^{1}$, Nahid Jalilvand ${ }^{2 *}$, Mohammad Kamali ${ }^{3}$, Mona Ebrahimipour ${ }^{4}$, Azar Mehri ${ }^{1}$

1. Department of Speech Therapy, School of Rehabilitation, Tehran University of Medical Sciences, Tehran, Iran.

2. Department of Speech Therapy, School of Rehabilitation Sciences, Iran University of Medical Sciences, Tehran, Iran.

3. Department of Basic Sciences, School of Rehabilitation Sciences, Iran University of Medical Sciences, Tehran, Iran.

4. Department of Speech Therapy, University of Social Welfare and Rehabilitation Sciences, Tehran, Iran.

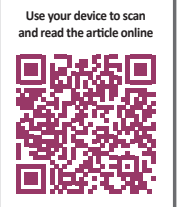

Citation: Safariyan N, Jalilvand N, Kamali M, Ebrahimipour M, Mehri A. The Verbal and Non-Verbal Communication Screening Checklist for Persian Speaking Children From 12 to 24 Months and Its Validity and Reliability. Iranian Rehabilitation Journal. 2017; 15(1):71-75. https://doi.org/10.18869/nrip.irj.15.1.71

https://doi.org/10.18869/nrip.irj.15.1.71

Article info:

Received: 14 Nov. 2016

Accepted: 30 Jan. 2017

\section{Keywords:}

Checklist, Communication, Verbal, Non-verbal, Typically developing children, Persian Language

\section{ABSTRACT}

Objectives: Identification of developmental disabilities in the initial years of life provides an opportunity for early intervention. However there are limitations in this procedure, like the lack of appropriate instruments. The purpose of this study was to develop a verbal and non-verbal communication screening instrument and determining its validity and reliability in Persianspeaking children aged between 12 and 24 months.

Methods: Parents of 147 children aged between 12 and 24 months participated in this study. Prior to the data collection, we reviewed communication tests and texts in Persian and English articles. We determined the content validity by calculating impact score of content validity ratio (CVR) and content validity index (CVI). Test-retest reliability was calculated within an interval of 1 week.

Results: The CVR score for the first group was between 0.57 and 1, and for the second group between 0.79 and 1 . These values were acceptable. CVI score for both groups was within 0.79-1 range. Impact score for items in the first group was 3-4.7, and in the second group 2.9-4.8. By calculating interclass correlation, the Cronbach $\alpha$ coefficient and Spearman's rho in two administrations within 1-week interval, the test-retest reliability was evaluated, which was acceptable.

Discussion: The findings of this study show that this checklist has reasonable validity and reliability for both groups. The checklist is an integrated instrument for screening children who are at risk of verbal and non-verbal communication delay or disorders. 


\section{Introduction}

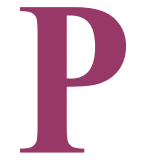

arents are usually worried about the delayed language development in their children and compare their expressive language abilities with other children. Kim and Sung mentioned that parents could provide exact details about their children's development, so it is better to use parent-completed questionnaires [1].

Parents can provide accurate information about their children's development; therefore, using a valid and reliable checklist or questionnaire will be useful for early detection of developmental disabilities in children. There are several parent questionnaires designed for evaluating language development and other developmental aspects in children. For example, the Parent Report of Children's Abilities-Revised (PARCA-R) is a questionnaire for clinical use. The validity of PARCA-R was reported by Blaggan et al. [2]. Scherer and D'Antonio reported the efficacy of the parent questionnaire for screening early language development in children with cleft palate. They found that the parent questionnaire can be a valid tool for screening language development [3]. Paradis et al. concluded that the Alberta Language and Development Questionnaire (ALDeQ) is a useful mean for obtaining information about language development [4].

The Ages and Stages Questionnaire (ASQ) is another parent tool for evaluating five developmental areas: communication, gross motor development, fine motor development, problem solving, and personal-social behavior [5]. The validity and reliability of the Persian version of the ASQ are reported by Vameghi et al. [6]. Jafari and Malayeri developed the Newsha Developmental scale as an integrated test for Persian-speaking children and reported its psychometric properties [7].

The Persian speech and language pathologists need valuable tools for early detection of developmental communication and speech and language disabilities in children. The verbal and non-verbal items in the Persian version of ASQ and Newsha Developmental scale are not enough for evaluating of Persian-speaking children who are at risk of language delay or disorders between 12 and 24 months of age.

The main purpose of this study was to develop a verbal and non-verbal communication screening instrument and then determine its validity and reliability in Persianspeaking children aged between 12 and 24 months.

\section{Methods}

\section{Participants}

Parents of 147 Persian-speaking children (81 girls and 66 boys) aged from 12 to 24 months, participated in this study. The children were divided into two groups based on their age levels. The first group comprised 70 children aged 12-18 months $(\mathrm{M}=15.16, \mathrm{SD}=2.15$ months $)$ and the second group were 77 children aged 18 - 24 months $(\mathrm{M}=20.47, \mathrm{SD}=1.90$ months $)$.

The participants were recruited from 35 kindergartens supervised by the Welfare Organization in Tehran. The parents who signed the consent form filled out the questionnaires by answering yes/no questions. Their children had no history or symptoms of movement delay, physical damage, neurological problems, seizures, brain damage, or any other disorders. To examine the temporal reliability, we randomly selected 30 parents with an interval of 1 week, and asked them to answer the questions again. This study was approved by the Ethics Committee of Tehran University of Medical Sciences. The participants were free to withdraw from the study at any stage.

\section{Procedures}

This investigation was conducted in two steps. At first step, we reviewed available resources for collecting verbal and non-verbal communication ability items in typically developing children aged 12-24 months [6-10]. We collected 95 items and developed a checklist composed of 46 items for children aged 12 to 18 months and 49 items for 18-24 months old children. An expert panel, including 14 speech and language pathologists received the checklist and evaluated the content validity of the items. The experts were asked to rate each item based on 3 point scale $(1=$ not necessary, $2=$ useful but not essential, $3=$ essential) to assess the necessity of items. Then the number of "essential" rates were calculated and the content validity ratio (CVR) was calculated $[11,12]$. The items with the scores higher than 0.51 were remained in the checklist [12]. According to the expert panel, the relevancy of items was examined by utilizing a 4-point Likert-type scale, and the content validity index (CVI) was calculated. The items that had CVI values over 0.79 were preserved [13].

Based on the opinions of 30 parents, the face validity of the checklist was determined. They were asked to assess the difficulty and ambiguity of each item on a 5-point Likert-type scale. Then, the impact score of 50 items 
were calculated. All the 50 items had score more than 1.5 and remained [14].

The face validity and content validity of 50 items were confirmed ( 25 items for the age range of 12 to 18 months and 25 items for age range of 18 to 24 months). The first version of the Persian verbal and non-verbal communication screening checklist was divided into four categories, including expressive language, receptive language, speech and non-verbal communication for 2 age levels; $12-18$ and 18-24 months. The reliability of the checklist was determined in the second step of the current study.

\section{Statistical Analysis}

Statistical analysis was carried out, using SPSS (Version 17). The mean and standard deviation for age were calculated for each participant. The KolmogorovSmirnov test at $\mathrm{P}>0.05$ significance was conducted, which indicated that the data were normally distributed; and hence, parametric testing was conducted. To calculate the internal consistency, the Cronbach $\alpha$ coefficient was calculated. It normally ranges between 0 and 1 . To examine temporal reliability (test-retest reliability) intra-class correlation coefficient (ICC) at $\mathrm{P}<0.05$ was performed. The significance level was set at $\mathrm{P}<0.05$.

\section{Results}

For determining content validity of the checklists, the CVR scores for both groups were calculated. It was found that CVR score for the first group was between 0.57 and 1 , and for the second group, between 0.79 and 1 , which are considered to be reasonable scores. The CVI score for both groups remained between 0.79 and 1 .

Face validity of the communication checklist was assessed by calculating the impact score. The impact score of items in the first group was between 3 and 4.7, and in the second group, between 2.9 and 4.8 (Figure 1).

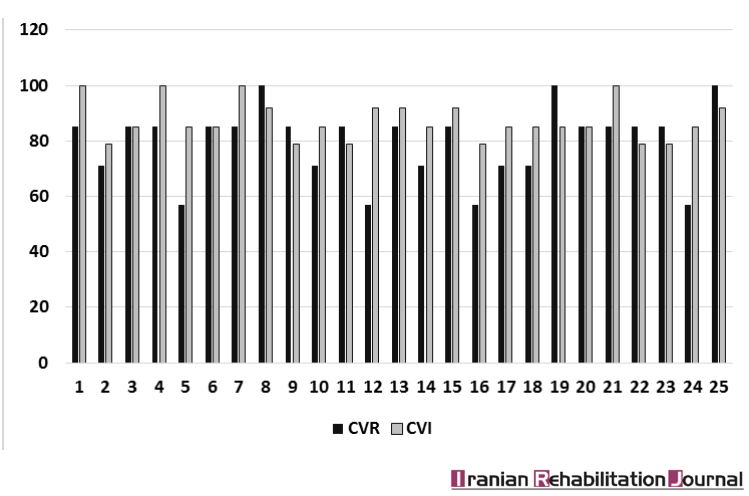

Figure 2. CVI and CVI scores for the checklist of first group

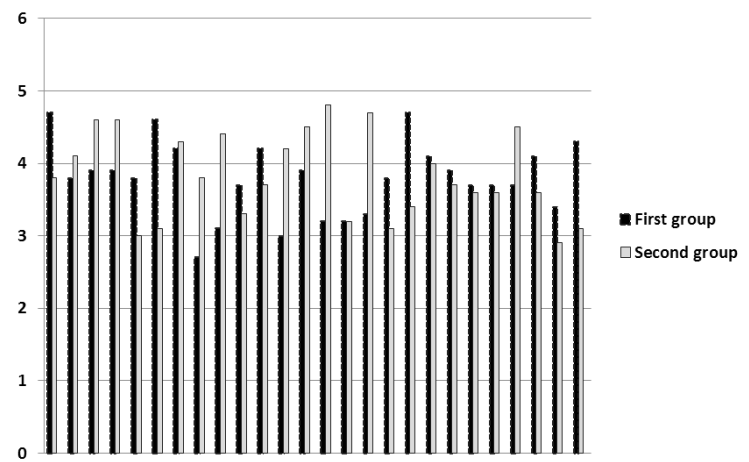

Iranian Rehabilitation Journal

Figure 1. Impact scores for the items of checklist for both groups

The mean (SD) of total scores were 21.86 (3.32) and 21.42 (3.51) in first group (12-18 months) and second group (18-24 months), respectively (Figures 2 and 3).

To calculate internal consistency, the Cronbach $\alpha$ coefficient was used, and the results are shown in Table 1. The test was administered twice within an interval of one week. Test-retest reliability was evaluated by calculating ICC, the Cronbach $\alpha$ coefficient, and Spearman's rho between the obtained scores of sub-scales. These results are tabulated in Tables 2 and 3 .

The mean scores of four subtests and the total scores were compared between two genders. The results indicated that there was no significant difference between two groups (Table 4).

\section{Discussion}

In the current study, the screening instrument with 50 items was developed for assessing verbal and nonverbal communication abilities in the Persian-speaking children aged 12 to 24 months. The psychometric properties of the instrument, including content validity (CVR and CVI), face validity, internal consistency, and temporal reliability were determined. The CVR scores showed that 50 items of the checklist were necessary. The CVI

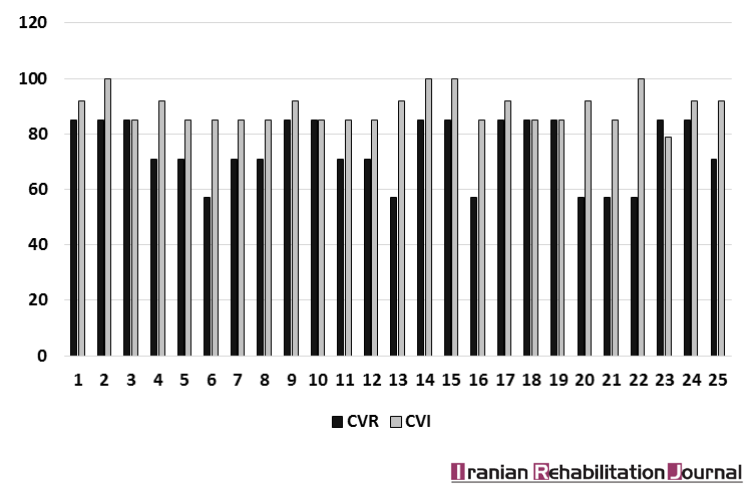

Figure 3. CVR and CVI scores for the checklist of second group 
Table 1. Cronbach's alpha coefficient for internal consistency in both groups

\begin{tabular}{cccccc}
\hline & Receptive language & Expressive language & Speech & Nonverbal Communication & Total \\
\hline First group & 0.711 & 0.710 & 0.714 & 0.709 & 0.718 \\
Second group & 0.715 & 0.766 & 0.855 & 0.721 & 0.722 \\
\hline
\end{tabular}

Ilranian Rehabilitation Journal

Table 2. Interclass correlation, Cronbach's alpha coefficient for reliability in both groups

\begin{tabular}{cccccccccccc}
\hline & \multicolumn{2}{c}{$\begin{array}{c}\text { Receptive } \\
\text { Language }\end{array}$} & \multicolumn{2}{c}{$\begin{array}{c}\text { Expressive } \\
\text { Language }\end{array}$} & Speech & \multicolumn{2}{c}{$\begin{array}{c}\text { Nonverbal } \\
\text { Communication }\end{array}$} & Total \\
\cline { 2 - 10 } & ICC & $\begin{array}{c}\text { Cronbach's } \\
\text { Alpha }\end{array}$ & ICC & $\begin{array}{c}\text { Cronbach's } \\
\text { Alpha }\end{array}$ & ICC & $\begin{array}{c}\text { Cronbach's } \\
\text { Alpha }\end{array}$ & ICC & $\begin{array}{c}\text { Cronbach's } \\
\text { Alpha }\end{array}$ & $\begin{array}{c}\text { ICC } \\
\text { Cronbach's } \\
\text { Alpha }\end{array}$ \\
\hline $\begin{array}{c}\text { First } \\
\text { group }\end{array}$ & 0.908 & 0.908 & 0.967 & 0.967 & 0.919 & 0.919 & 0.982 & 0.982 & 0.844 & 0.844 \\
$\begin{array}{c}\text { Second } \\
\text { group }\end{array}$ & 0.911 & 0.911 & 0.958 & 0.958 & 0.970 & 0.970 & 0.949 & 0.949 & 0.852 & 0.852 \\
\hline
\end{tabular}

Iranian Rehabilitation Journal

Table 3. Correlation between scores in both groups

\begin{tabular}{|c|c|c|c|c|c|c|c|c|c|c|}
\hline & \multicolumn{2}{|c|}{$\begin{array}{l}\text { Receptive } \\
\text { Language }\end{array}$} & \multicolumn{2}{|c|}{$\begin{array}{l}\text { Expressive } \\
\text { Language }\end{array}$} & \multicolumn{2}{|c|}{ Speech } & \multicolumn{2}{|c|}{$\begin{array}{c}\text { Nonverbal } \\
\text { Communication }\end{array}$} & \multicolumn{2}{|l|}{ Total } \\
\hline & $\begin{array}{l}\text { Correlation } \\
\text { Coefficient }\end{array}$ & sig. & $\begin{array}{l}\text { Correlation } \\
\text { Coefficient }\end{array}$ & sig. & $\begin{array}{l}\text { Correlation } \\
\text { Coefficient }\end{array}$ & sig. & $\begin{array}{l}\text { Correlation } \\
\text { Coefficient }\end{array}$ & sig. & $\begin{array}{l}\text { Correlation } \\
\text { Coefficient }\end{array}$ & sig. \\
\hline $\begin{array}{l}\text { First } \\
\text { group }\end{array}$ & 0.828 & 0.000 & 0.835 & 0.000 & 0.847 & 0.000 & 0.971 & 0.000 & 0.952 & 0.000 \\
\hline $\begin{array}{l}\text { Second } \\
\text { group }\end{array}$ & 0.719 & 0.000 & 0.896 & 0.000 & 0.907 & 0.000 & 0.613 & 0.000 & 0.948 & 0.000 \\
\hline
\end{tabular}

Ilranian Rehabilitation Journal

Table 4. Mean score for four subtests and total in both groups

\begin{tabular}{|c|c|c|c|c|c|c|c|c|c|c|c|c|c|c|c|}
\hline & \multicolumn{3}{|c|}{$\begin{array}{l}\text { Receptive } \\
\text { Language }\end{array}$} & \multicolumn{3}{|c|}{$\begin{array}{l}\text { Expressive } \\
\text { Language }\end{array}$} & \multicolumn{3}{|c|}{ Speech } & \multicolumn{3}{|c|}{$\begin{array}{c}\text { Nonverbal } \\
\text { Communication }\end{array}$} & \multicolumn{3}{|c|}{ Total } \\
\hline & \multicolumn{2}{|c|}{ Mean Rank } & \multirow{2}{*}{ sig. } & \multicolumn{2}{|c|}{ Mean Rank } & \multirow{2}{*}{ sig. } & \multicolumn{2}{|c|}{ Mean Rank } & \multirow{2}{*}{ Sig. } & \multicolumn{2}{|c|}{ Mean Rank } & \multirow{2}{*}{ sig. } & \multicolumn{2}{|c|}{ Mean Rank } & \multirow{2}{*}{ sig. } \\
\hline & Boy & Girl & & Boy & Girl & & Boy & Girl & & Boy & Girl & & Boy & Girl & \\
\hline $\begin{array}{l}\text { First } \\
\text { group }\end{array}$ & 33.58 & 37.03 & 0.42 & 32.73 & 37.71 & 0.28 & 35.11 & 35.81 & 0.81 & 31.37 & 38.78 & 0.10 & 31.92 & 38.35 & 0.18 \\
\hline $\begin{array}{l}\text { Second } \\
\text { group }\end{array}$ & 37.31 & 40.40 & 0.44 & 36.63 & 40.98 & 0.38 & 36.93 & 40.73 & 0.38 & 33.77 & 40.02 & 0.59 & 36.34 & 41.21 & 0.33 \\
\hline
\end{tabular}

scores revealed that the items are simple, relevant, and obvious. Therefore, the checklist has a satisfying content validity. The impact scores showed that the checklist has a high face validity.

The Cronbach $\alpha$ is the most common measure for assessing the reliability and also determining internal consistency. In the current study, the Cronbach $\alpha$ for the total score in two groups, and for subscales were $\geq 0.70$. According to George and Mallery, the value of $\alpha \geq 0.70$ is acceptable [15]. Thus, the checklist has a satisfying internal consistency.

The intra-class correlation coefficient (ICC) was more than 0.80 . According to Portney and Watkins, ICC value more than 0.75 is an acceptable value for the reliability [16]. The value of inter-rater reliability for communication domain in the Persian version of the Ages and Stages questionnaires, was reported 0.88 by Vameghi et al. Therefore, this level of temporal reliability is accept- 
able, indicating that the results of the checklist will be stable over time.

We compared the scores between two groups based on gender and as it was expected, there was no significant difference between girls and boys. In many studies verbal and non-verbal communication skills have been compared. Jafari et al. reported no significant difference between girls and boys in the majority of items in the Newsha test as well [7].

\section{Conclusion}

In conclusion, the findings revealed that the verbal and non-verbal communication screening checklist for Persian-speaking children, aged between 12 and 24 months, has a reasonable content validity and a satisfying reliability (internal consistency and temporal reliability). Persian speech and language pathologists could use this checklist for determining whether a child is at risk of speech and language delay or disorder.

\section{Acknowledgements}

This research was supported by a research grant from Tehran University of Medical Sciences. The authors are grateful to the parents of the children who participated in this study.

\section{Conflict of Interest}

The authors declared no conflict of interests.

\section{References}

[1] Kim EY, Sung IK. The ages and stages questionnaire: screening for developmental delay in the setting of a pediatric outpatient clinic. Korean Journal of Pediatrics. 2007; 50(11):10611066. doi: 10.3345/kjp.2007.50.11.1061.

[2] Blaggan S, Guy A, Elaine M. Boyle E M, Spata E, Manktelow B N, Wolke D, Johnson S. A Parent Questionnaire for Developmental Screening in Infants Born Late and Moderately Preterm. Pediatrics. 2014; 134(1): 57-62.

[3] Scherer NJ, D'Antonio LL. The parent questionnaire for screening early language development in children with cleft palate. Cleft palate Craniofac J.1995. 32(1): 7-13.

[4] Paradis, J, Emmerzael K, Sorenson Duncan T. Assessment of English language learners: using parent report on first language development. Journal of Communication Disorders, 2010, 43: 474-497.
[5] Bricker D, Squires J, Mounts L. Ages and Stages Questionnaires: A Parent-completed, Child-monitoring System. Baltimore (MD): Paul H. Brookes; 1999.

[6] Vameghi R, Sajedi F, Kraskian Mojembari A, Habibollahi A, Lornezhad H R, Delavar B. Cross-Cultural Adaptation, Validation and Standardization of Ages and Stages Questionnaire (ASQ) in Iranian Children. Iranian Journal of Public Health. 2013;42(5):522-528.

[7] Jafari Z, Malayeri S. The Psychometric Properties of Newsha Developmental Scale: an Integrated Test for Persian Speaking Children. Iranian Journal of Pediatrics, 2012;22(1), 28-34.

[8] Malayeri S, Jafari Z, Ashayeri H. NEWSHA Developmental Scale for Persian $\neg$ Language Children. Tehran: Danjeh Publication. 2009.

[9] Jalilevand N. Speech \& language development in Farsi speaking children (Persian). Tehran: Danjeh Publication. 2010

[10] Mundy P, Delgado C, Block J, Venezia M, Hogan A, Seibert J. Early social communication scale. MIND Institute, University of California at Davis, USA. 2013.

[11] Lawshe CH. A quantitative approach to content validity. Phrsonnhl Psychoi Ogy 1975; 28: 563-75.

[12] Shultz K, Whitney D. Measurement theory in action: Case studies and exercises. California: Sage Publication; 2005

[13] Polit DF, Beck CT, Owen SV. Is the CVI an acceptable indicator of content validity? Appraisal and recommendations. Research in Nursing \& Health. 2007; 30(4):459-67. doi: 10.1002/nur.20199

[14] Broder HL, McGrath C, Cisneros GJ: Questionnaire development: face validity and item impact testing of the Child Oral Health Impact Profile. Community Dent Oral Epidemiol 2007, 35: 8-19.

[15] George D, Mallery P. SPSS for Windows step by step: A simple guide and reference. 11.0 update (4th ed.). Boston: $\mathrm{Al}$ lyn \& Bacon. 2003.

[16] Portney LG, Watkins MP. Foundations of clinical research: applications to practice. 2nd ed. Upper Saddle River, NJ: Prentice Hall Health; 2000. 